\title{
Mechanical Properties of PMMA-Sepiolite Nanocellular Materials with a Bimodal Cellular Structure
}

\author{
Victoria Bernardo,* Frederik Van Loock, Judith Martin-de Leon, Norman A. Fleck, \\ and Miguel Angel Rodriguez-Perez
}

Bimodal cellular poly(methyl methacrylate) with micro- and nano-sized $(300-500 \mathrm{~nm})$ cells with up to $5 \mathrm{wt} \%$ of sepiolite nanoparticles and porosity from $50 \%$ to $75 \%$ are produced by solid-state foaming. Uniaxial compression tests are performed to measure the effect of sepiolite concentration on the elastic modulus and the yield strength of the solid and cellular nanocomposites. Single edge notch bend tests are conducted to relate the fracture toughness of the solid and cellular nanocomposites to sepiolite concentration. The relative modulus is independent of sepiolite content to within material scatter when considering the complete porosity range. In contrast, a mild enhancement of the relative modulus is observed by the addition of sepiolite particles for the foamed nanocomposites with a porosity close to $50 \%$. The relative compressive strength of the cellular nanocomposites mildly decreases as a function of sepiolite concentration. A strong enhancement of the relative fracture toughness by the addition of sepiolites is observed. The enhancement of the relative fracture toughness and the relative modulus (at $50 \%$ porosity) can be attributed to an improved dispersion of the particles due to foaming and the migration of micro-sized aggregates from the solid phase to the microcellular pores during foaming.

\section{Introduction}

Nanocellular polymers are polymer foams characterized by cell sizes in the range of tens to hundreds of nanometers. ${ }^{[1]}$ An attractive property of these nanocellular polymers is their low thermal conductivity due to the Knudsen effect. ${ }^{[2,3]}$ Theoretically, the reductions in the thermal conduction of the gas phase start to be significant in comparison with microcellular polymers for cell sizes under $500 \mathrm{~nm}$. Moreover, recently,

V. Bernardo, J. Martin-de Leon, Prof. M. A. Rodriguez-Perez

Cellular Materials Laboratory (CellMat)

Condensed Matter Physics Department

University of Valladolid

Paseo de Belén 7, 47011 Valladolid, Spain

E-mail:vbernardo@fmc.uva.es

F. Van Loock, Prof. N. A. Fleck

Engineering Department

University of Cambridge

Trumpington Street, CB2 1PZ, Cambridge, UK

The ORCID identification number(s) for the author(s) of this article can be found under https://doi.org/10.1002/mame.201900041.

DOI: 10.1002/mame.201900041 semi-transparent nanocellular foams have been reported ${ }^{[4,5]}$ and, due to their nano-sized cell size, these materials have the potential to be used in membranes for ultrafiltration or in catalysis and sensors. ${ }^{[6-8]}$ Most research on nanocellular polymers is focused on their production, whereas the literature on the mechanical characterization is relatively scarce. Notario et al. ${ }^{[9]}$ found that the material performance index for a light, stiff beam in bending $E^{1 / 2} / \rho$ (where $E$ is the Young's modulus and $\rho$ is the density) for a nanocellular foam exceeded that for a microcellular foam. ${ }^{[10]}$ They attributed this stiffening to the fact that the size of the cell walls of the nanocellular material is in the order of the radius of gyration of a poly(methyl methacrylate) (PMMA) molecule..$^{[9]}$ Miller and co-workers ${ }^{[11]}$ found that micro- and nanocellular polyetherimide (PEI) have similar values for $E$ whereas the nanocellular PEI materials had a greater impact resistance. Guo[ ${ }^{[2]}$ observed that micro- and nanocellular polycarbonate (PC) have similar values of $E / \rho$ and similar impact resistance properties for cellular materials with relative densities higher than 0.6. In the case of polymer blends, Wang and coworkers ${ }^{[13]}$ reported that nanocellular polymers produced with PMMA blended with thermoplastic polyurethane (TPU) showed higher tensile toughness and impact toughness compared to microcellular PMMA. For polypropylene (PP) blended with polytetrafluoroethylene (PTFE), Wang et al. ${ }^{[14]}$ showed that a nanocellular sample based on PP/PTFE has a higher impact strength than conventional PP cellular material. Reglero-Ruiz et al. ${ }^{[15]}$ measured the elastic modulus for nanocellular samples based on nanostructured (poly(methyl methacrylate)-[PMMA]poly(butyl acrylate)-PMMA).

The addition of inorganic nanoparticles to a polymer matrix is a common strategy to improve the mechanical properties of a polymer. ${ }^{[16-20]}$ When these nanocomposites are foamed, the resulting cellular nanocomposites inherit this reinforcement and this strategy could be used to further enhance the mechanical properties of nanocellular foams. ${ }^{[21,22]}$ In addition, nano-sized particles have successfully been used as heterogeneous nucleation agents for the production of micro-[23-26] and nanocellular ${ }^{[27-31]}$ polymers. The addition of nanoparticles is therefore a promising method to enhance the mechanical 
performance of nanocellular polymers. In the recent work of Yeh et al., ${ }^{[32]}$ the addition of nanoclays was proved to enhance the modulus and yield strength of nanocellular TPU. However, the authors have been unable to locate any more studies that investigate the effect of nanoparticles on the mechanical properties of nanocellular polymers.

In the present study, PMMA is reinforced with nano-sized needle-like sepiolites, and cellular materials are produced by gas dissolution foaming. The effect of the sepiolite concentration on the mechanical properties (such as the compressive yield strength, the compressive elastic modulus, and the fracture toughness) of the solid and cellular nanocomposites is measured. In an earlier work ${ }^{[31]}$ we showed that the addition of sepiolites, modified with a quaternary ammonium salt, in a PMMA matrix resulted in bimodal cellular structures comprising micro- and nano-sized (300-500 nm) cells. In this paper, our goal is to analyze the mechanical behavior of bimodal nanocellular polymers based on PMMA/sepiolite nanocomposites with various particle concentrations and densities, and to determine the effect of the addition of sepiolites particles on their mechanical properties. For this purpose, a detailed characterization of the samples produced in the paper has been carried out.

\section{Experimental Section}

\subsection{Materials}

Polymethylmethacrylate (PMMA) V 825T $\left(M_{\mathrm{n}}=43 \mathrm{~kg} \mathrm{~mol}{ }^{-1}\right.$, $M_{\mathrm{w}}=83 \mathrm{~kg} \mathrm{~mol}^{-1}$ ) was supplied by ALTUGLAS International in the form of pellets with a density $(\rho)$ of $1.18 \mathrm{~g} \mathrm{~cm}^{-3}$ and a glass transition temperature $\left(T_{g}\right)$ close to $114.5^{\circ} \mathrm{C}$ as measured by DSC. Sepiolites were provided by Tolsa S.A (Spain). These particles are hydrated magnesium silicates. Sepiolites present a needle-like morphology, with an average particle length ranging from 1 to $2 \mu \mathrm{m}$ and a diameter in the nanometer range (between 20 and $30 \mathrm{~nm}$ ). ${ }^{[3,34]}$ The sepiolites used in this work have been modified with a quaternary ammonium salt. The process to obtain and modify these particles is detailed elsewhere. ${ }^{[35,36]}$ Medical grade carbon dioxide $\left(\mathrm{CO}_{2}\right)$ (99.9\% purity) was used as the blowing agent for the gas dissolution foaming experiments.

\subsection{Solid Blends Production}

Blends of PMMA with varying sepiolite contents were compounded using a twin-screw extruder model COLLIN TEACHLINE ZK 25T, with L/D equal to 24 and screw diameter equal to $25 \mathrm{~mm}$ (Table 1). PMMA and sepiolites were dried in a vacuum oven at $50{ }^{\circ} \mathrm{C}$ for $12 \mathrm{~h}$ before blending. The temperature profile set on the extruder was from $160{ }^{\circ} \mathrm{C}$ at the hopper to $200{ }^{\circ} \mathrm{C}$ in the die. The screw speed was equal to $40 \mathrm{rpm}$. The produced blends were cooled in a water bath and pelletized. After drying the pellets for $2 \mathrm{~h}$ in a vacuum oven at a temperature equal to $50{ }^{\circ} \mathrm{C}$, each blend was extruded again using the same processing conditions to have a homogeneous dispersion of the particles.
Table 1. The PMMA-sepiolite blend formulations.

\begin{tabular}{lc}
\hline Material ID & Sepiolite concentration [wt\%] \\
\hline PMMA & 0 \\
$1 \%-S$ & 1 \\
$2 \%-S$ & 2 \\
$3 \%-S$ & 3 \\
$5 \%-S$ & 5 \\
\hline
\end{tabular}

Next, the obtained pellets were compression molded into solid sheets of $155 \times 75 \times 4 \mathrm{~mm}^{3}$ using a hot plate press provided by Remtex. The pellets were first dried in a vacuum oven at $50{ }^{\circ} \mathrm{C}$ overnight before processing. Subsequently, they were made molten by holding them at $250{ }^{\circ} \mathrm{C}$ for $500 \mathrm{~s}$ and then compacted at $250{ }^{\circ} \mathrm{C}$ with a constant pressure of $17 \mathrm{MPa}$ for $60 \mathrm{~s}$. Finally, the sheets were cooled down to room temperature with the pressure of $17 \mathrm{MPa}$ maintained. Rectangular specimens with dimensions corresponding to $50 \times 15 \times 4 \mathrm{~mm}^{3}$ were machined from the sheet for the foaming experiments. Note that PMMA absent the sepiolite was processed under the same conditions for comparison purposes.

\subsection{Gas Dissolution Foaming Experiments}

Foaming experiments were performed using a pressure vessel (model PARR 4681) provided by Parr Instrument Company with a capacity of $1 \mathrm{~L}$. The maximum temperature and pressure reached by the pressure vessels correspond to $350{ }^{\circ} \mathrm{C}$ and $41 \mathrm{MPa}$, respectively. The pressure is automatically controlled by a pressure pump controller (model SFT-10) provided by Supercritical Fluid Technologies Inc. The vessel is equipped with a clamp heater of $1200 \mathrm{~W}$, and its temperature is regulated via a CAL 3300 temperature controller. Foaming experiments were conducted by a two-step foaming process. ${ }^{[37]}$ First, samples were put into the pressure vessel at a constant $\mathrm{CO}_{2}$ pressure $\left(p_{\text {sat }}=10 \mathrm{MPa}\right)$ and temperature $\left(T_{\text {sat }}=25^{\circ} \mathrm{C}\right)$ for the saturation stage. At these conditions, full saturation of $\mathrm{CO}_{2}$ in PMMA is achieved within $20 \mathrm{~h}^{[31]}$ The pressure was progressively released to ambient pressure with an instantaneous pressure drop rate of $15 \mathrm{MPa} \mathrm{s}^{-1}$ at the first pressure drop. The total depressurization time was around $30 \mathrm{~s}$.

The foaming step was carried out in a hot and cold plates press from Remtex. ${ }^{[38]}$ Details about this foaming process can be found in the Supporting Information. To obtain materials with different densities, the temperature of the press and the foaming time were varied (see Table 2). After the foaming step in the hot and cold plates press, flat samples, suitable for mechanical characterization, were obtained. From these pieces,

Table 2. Foaming parameters in the press.

\begin{tabular}{lcc}
\hline Target relative density & Temperature $\left[{ }^{\circ} \mathrm{C}\right]$ & Time $[\mathrm{s}]$ \\
\hline High $(\approx 0.5)$ & 40 & 300 \\
Medium $(\approx 0.35)$ & 60 & 300 \\
Low $(\approx 0.3)$ & 100 & 60 \\
\hline
\end{tabular}


samples with adequate dimensions for the different mechanical tests (see Section 2.4.5) were machined using a band sawing machine. For the blend with the highest particle content $15 \%$ $\mathrm{S})$, it was only possible to produce the materials with high relative densities, as the presence of too many aggregates of the sepiolites particles led to cracking of the samples at the highest foaming temperatures used to produce the low and medium relative density cellular nanocomposites.

\subsection{Characterization}

\subsubsection{Density}

The density of the solid nanocomposites was measured with a gas pycnometer (Mod. AccuPyc II 1340, Micromeritics). The density of the cellular materials was determined with the water-displacement method based on the Archimedes' principle using a density determination kit for an AT261 MettlerToledo balance. The solid skin of the samples was removed with a polisher (model LaboPO12-LaboForce3, Struers) by polishing off $200 \mu \mathrm{m}$ from the top and bottom faces of the sample before measuring their densities. Further polish did not change the density, indicating that the density is homogeneous through the sample thickness. The relative density $\left(\rho_{r}\right)$ is defined as the ratio of the cellular material density $(\rho)$ to the density of the solid nanocomposite with the same composition $\left(\rho_{s}\right)$.

\subsubsection{Cellular Structure}

Samples were immersed in liquid nitrogen and then fractured for microscopic visualization and coated with gold using a sputter coater (model SCD 005, Balzers Union). The cellular structure of the samples was analyzed using an ESEM Scanning Electron Microscope (QUANTA 200 FEG). Dedicated in-house software based on ImageJ/FIJI was used for this purpose. ${ }^{[39]}$ First, the average cell size $(\phi)$ was measured and the standard deviation of the cell size distribution $(S D)$ was obtained. The parameter $S D / \phi$ was calculated as an indicator of the homogeneity of the cellular structure. The nanocomposite cellular materials of this work possess a bimodal cellular structure with micro-sized cells (above $1 \mu \mathrm{m}$ ) and nano-sized cells (below $1 \mu \mathrm{m}$ ), and values for the average cell size $\phi$ and standard deviation $S D$ were measured for both distributions. The average cell size was written as $\phi_{1}$ for the nano-sized cells and as $\phi_{2}$ for the micro-sized cells. Similarly, $S D_{1}$ refers to the standard deviation of the cell size distribution of the nanosized cells and $S D_{2}$ denotes the standard deviation of the cell size distribution of the micro-sized cells. The anisotropy ratio $A R$ was measured as the ratio between the average cell size of the whole population of cells observed in the plane aligned with the compression moulding direction to the average cell size of the whole population of cells measured in the plane perpendicular to the compression molding direction. Cell density $\left(N_{v}\right)$ and cell nucleation density $\left(N_{0}\right)$ were determined from the SEM images using Kumar's theoretical approximation ${ }^{[40]}$ according to

$$
\begin{aligned}
& N_{v}=\left[\frac{n}{A}\right]^{3 / 2} \\
& N_{0}=\frac{N_{v}}{\rho_{r}}
\end{aligned}
$$

where $n$ is the number of cells in the SEM image and $A$ is the area of the image. Note that more than 200 cells from various regions of each cellular material were analyzed.

In this work, bimodal cellular structures (with cell sizes in the micro and the nano scale) are obtained. The observed cellular structures were found to have a much larger proportion of nano-sized cells than micro-sized cells. The micro-sized cells, however, typically occupied a significant volume of the sample, in the range from $20 \%$ to $40 \%$. To quantify the observed bimodality, the relative volume occupied by the population of nanosized cells, $V_{\text {nano, }}$ is measured. ${ }^{[31]}$

$V_{\text {nano }}=\frac{A_{t}-A_{m}}{A_{t}}$

where $A_{m}$ is the observed area occupied by the micro-sized cells (cell size above $1 \mu \mathrm{m}$ ) in the SEM images, and $A_{t}$ the total area of the image. The resulting 2D area ratio should be equivalent to the $3 \mathrm{D}$ volume ratio when an adequate amount of surfaces are analyzed, according to Delesse principle in stereology. ${ }^{[4,42]}$

\subsubsection{Open Cell Content}

The open cell content of the cellular materials was measured according to the ASTM D6226-10 standard using a gas pycnometer (Mod. AccuPyc II 1340, Micromeritics). The open cell content ratio $O C$ is defined as

$O C=\frac{V-V_{p}-V_{s}}{V\left(1-\rho_{r}\right)}$

where $V$ is the geometric volume of the sample, $V_{p}$ is the volume measured by the pycnometer, and $V_{s}$ is a penalty volume to account for the exposed cells at the surface of the sample. The geometric volume was determined from the cellular material density (measured by the water-displacement method) and its mass $(m)$ (measured with an AT261 MettlerToledo balance) as $V=m / \rho$. $V_{p}$ was determined by performing a pressure scan (from 0.02 to $0.13 \mathrm{MPa}$ ) in the gas pycnometer and measuring the pycnometric volume for each pressure. It was assumed that no more gas is able to enter the interconnected open cells when the measured volume remains constant for an increase in pressure. $V_{p}$ was calculated as the average of these last measured constant volume values. Note that, as $V_{s}$ is proportional to the cell size, this value becomes negligible for micro and nanocellular materials.

\subsubsection{X-Ray Analysis}

X-ray imaging is employed to determine the number of particle aggregates in the nanocomposite material. For this purpose, 
X-ray tomography images of both solid and cellular materials were taken with a spatial resolution of $2.5 \mu \mathrm{m}$ (i.e., aggregates with dimensions larger than $2.5 \mu \mathrm{m}$ can be detected). ${ }^{[43]}$ The mass of the aggregates is calculated by measuring the volume occupied by the aggregates and taking into account the real volume fraction of particles in the sample.

In addition, all samples were analyzed by X-ray radiography ${ }^{[44]}$ and those samples presenting defects or inhomogeneities were excluded from the mechanical tests.

\subsubsection{Mechanical Tests}

Mechanical properties in uniaxial compression were measured using an Instron 5584 electromechanical testing machine. Specimens were cuboids with in-plane dimensions $10 \times 10 \mathrm{~mm}^{2}$; the thickness varied from 4 to $6 \mathrm{~mm}$ depending on the relative density of the sample. The compression direction was perpendicular to the compression molding direction. At least three specimens were tested per material system. Tests were carried out at a crosshead velocity equal to $0.5 \mathrm{~mm} \mathrm{~min}^{-1}$, corresponding to a strain rate equal to $8.3 \times 10^{-4} \mathrm{~s}^{-1}$. Displacement of the platens was measured via a laser extensometer. All tests were conducted at room temperature.

Single edge notch three point bending (SENB) tests were performed at room temperature with an Instron 5584 test bench at a constant crosshead speed of $10 \mathrm{~mm} \mathrm{~min}^{-1}$. Specimens were cuboids with in-plane dimensions $55 \times 15 \mathrm{~mm}^{2}$; the thickness varied from 4 to $6 \mathrm{~mm}$ depending on the relative density of the sample. The critical mode I stress intensity factor $K_{I c}$ was calculated as a measure for the fracture toughness in accordance with the ASTM D5045-14. ${ }^{[45]}$ A pre-crack with a sharp tip was made at the end of a sawed notch by tapping with a razor blade.

\section{Results and Discussion}

\subsection{Cellular Structure}

Representative cellular structures of the cellular materials with a relative density close to 0.5 are shown in Figure 1 (SEM images from the plane parallel to the compression molding direction). At very low magnification (first row of Figure 1), a homogeneous structure is observed for PMMA, whereas the blends with sepiolites have a heterogeneous structure with pore sizes exceeding $100 \mu \mathrm{m}$. Using a higher magnification, one can observe the microcellular structure of the pure PMMA and the blends with sepiolites (see second row of Figure 1). The cell size distribution of the pure PMMA is unimodal; there are no nano-sized pores present (see third row of Figure 1 where an even higher magnification is used). In contrast, the PMMA/ sepiolite blends have a bimodal cell size distribution, the dominant population of cells is nanocellular (ranging from 300 to $500 \mathrm{~nm}$ ) as detailed below (see the third row in Figure 1). Earlier work demonstrated that sepiolites modified with a quaternary ammonium salt act as a nucleating agent during gas
PMMA
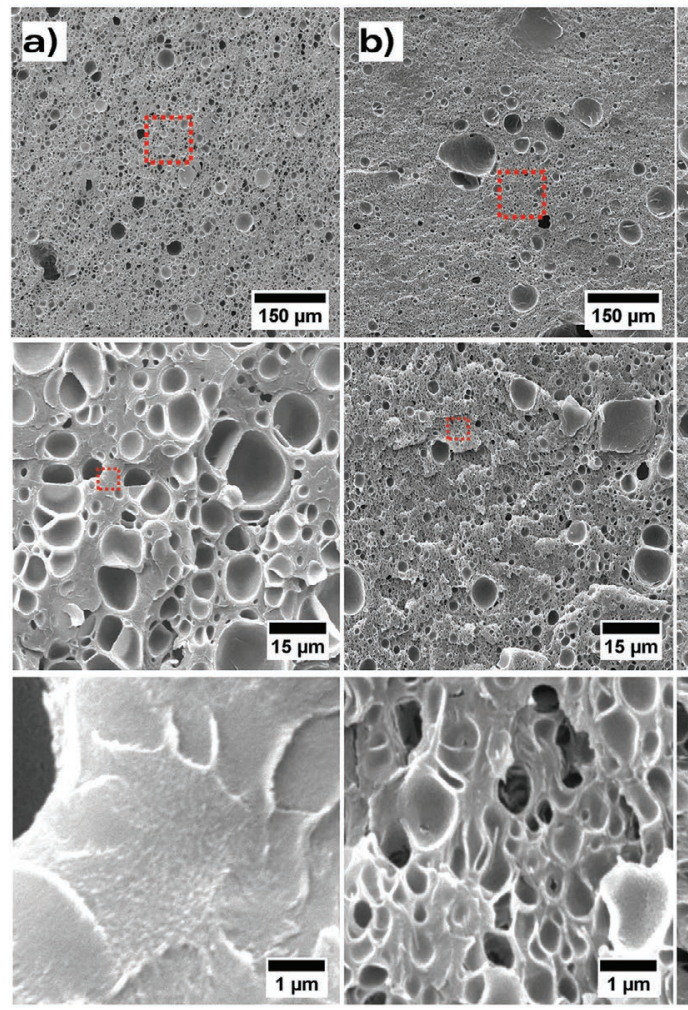

$2 \%-S$

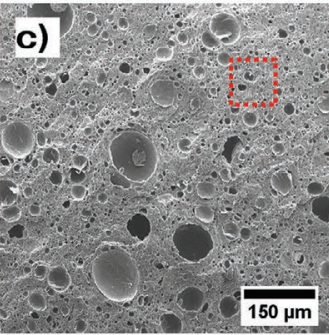

$3 \%-5$
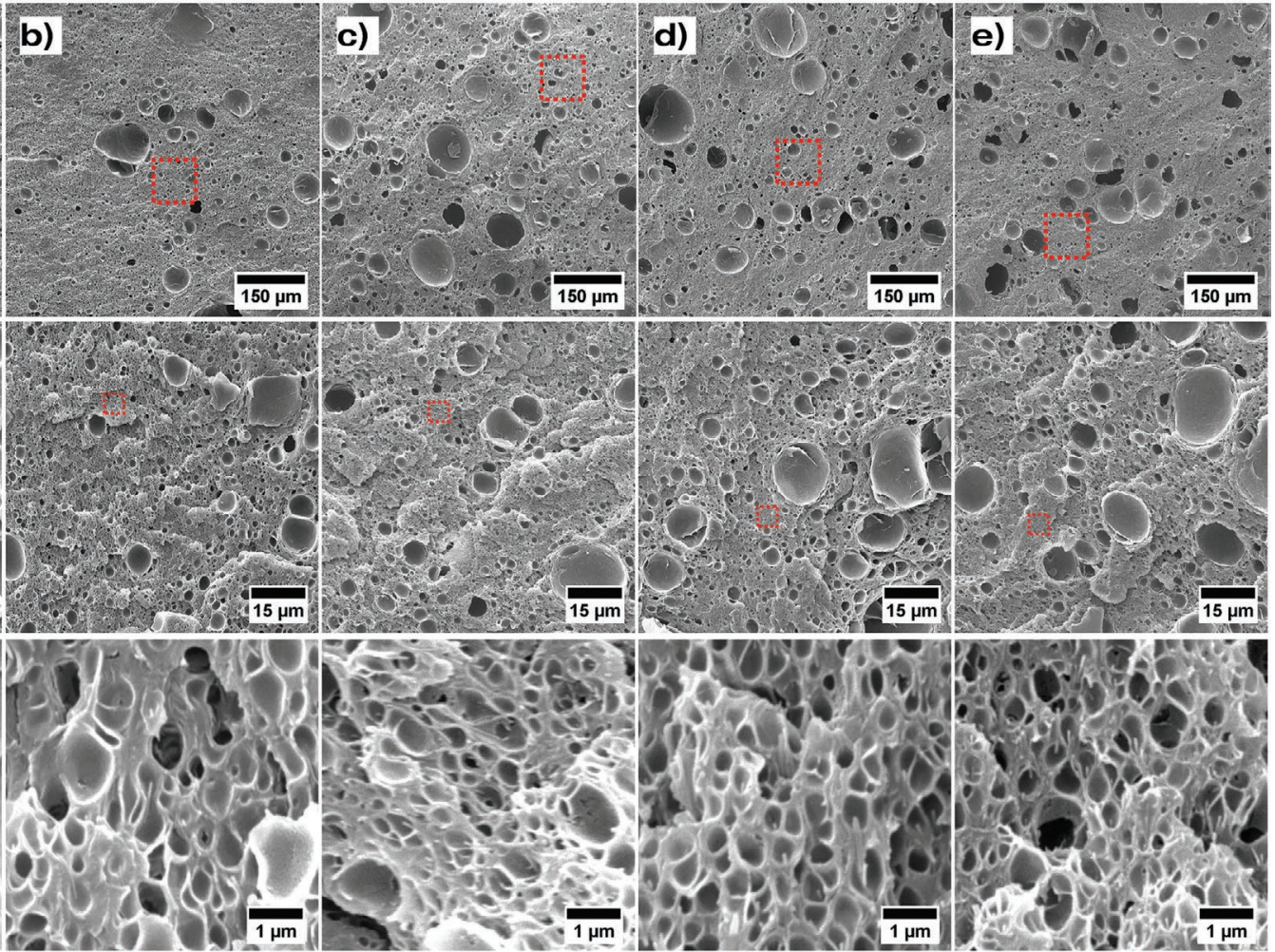

Figure 1. SEM images of the samples produced at a foaming temperature equal to $40{ }^{\circ} \mathrm{C}$ and foaming time equal to 5 min: a) PMMA, b) $1 \%-\mathrm{S}$, c) $2 \%-S$, d) $3 \%-S$, and e) $5 \%-S$. 
Table 3. Measured cellular structure parameters and open cell content of the cellular samples produced in this work.

\begin{tabular}{|c|c|c|c|c|c|c|c|c|c|c|}
\hline \# & Material & $\begin{array}{l}\text { Relative } \\
\text { density }\end{array}$ & $\begin{array}{l}\text { Cell nucleation density } \\
\text { [nuclei } \mathrm{cm}^{-3} \text { ] }\end{array}$ & $V_{\text {nano }}$ & $\phi_{1}[\mathrm{~nm}]$ & $\mathrm{SD}_{1} / \phi_{1}$ & $\phi_{2}[\mu \mathrm{m}]$ & $\mathrm{SD}_{2} / \phi_{2}$ & $A R$ & $O C$ \\
\hline 1 & PMMA & $0.52 \pm 0.04$ & $2.1 \cdot 10^{10}$ & 0.00 & 4300 & 0.77 & - & - & $1.1 \pm 0.4$ & 0.077 \\
\hline 2 & $1 \%-\mathrm{S}$ & $0.50 \pm 0.02$ & $1.2 \cdot 10^{13}$ & 0.75 & 460 & 0.51 & 3.4 & 0.92 & $1.3 \pm 0.5$ & 0.097 \\
\hline 3 & $2 \%-S$ & $0.51 \pm 0.02$ & $2.9 \cdot 10^{13}$ & 0.79 & 350 & 0.52 & 3.7 & 1.08 & $1.0 \pm 0.5$ & 0.057 \\
\hline 4 & $3 \%-S$ & $0.53 \pm 0.01$ & $2.0 \cdot 10^{13}$ & 0.61 & 330 & 0.72 & 3.1 & 1.07 & $1.1 \pm 0.5$ & 0.086 \\
\hline 5 & $5 \%-S$ & $0.47 \pm 0.02$ & $3.1 \cdot 10^{13}$ & 0.66 & 310 & 0.66 & 3.6 & 1.02 & $1.1 \pm 0.4$ & 0.059 \\
\hline 6 & PMMA & $0.35 \pm 0.01$ & $7.0 \cdot 10^{10}$ & 0.0 & 3200 & 0.92 & - & - & $1.2 \pm 0.5$ & 0.065 \\
\hline 7 & $1 \%-\mathrm{S}$ & $0.38 \pm 0.04$ & $1.6 \cdot 10^{13}$ & 0.71 & 440 & 0.56 & 4.0 & 0.74 & $1.1 \pm 0.4$ & 0.041 \\
\hline 8 & $2 \%-S$ & $0.35 \pm 0.01$ & $1.2 \cdot 10^{13}$ & 0.55 & 420 & 0.69 & 5.0 & 1.00 & $1.2 \pm 0.5$ & 0.049 \\
\hline 9 & $3 \%-5$ & $0.35 \pm 0.01$ & $1.3 \cdot 10^{13}$ & 0.61 & 420 & 0.72 & 7.2 & 0.80 & $1.4 \pm 0.7$ & 0.070 \\
\hline 10 & PMMA & $0.29 \pm 0.04$ & $4.5 \cdot 10^{10}$ & 0.00 & 3900 & 0.92 & - & - & $1.1 \pm 0.5$ & 0.020 \\
\hline 11 & $1 \%-\mathrm{S}$ & $0.33 \pm 0.03$ & $1.0 \cdot 10^{13}$ & 0.60 & 500 & 0.66 & 4.9 & 0.65 & $1.1 \pm 0.5$ & 0.029 \\
\hline 12 & $2 \%-S$ & $0.32 \pm 0.03$ & $4.4 \cdot 10^{13}$ & 0.82 & 390 & 0.51 & 5.7 & 1.06 & $1.2 \pm 0.4$ & 0.049 \\
\hline 13 & $3 \%-S$ & $0.27 \pm 0.02$ & $1.7 \cdot 10^{13}$ & 0.66 & 480 & 0.60 & 4.7 & 0.76 & $1.2 \pm 0.4$ & 0.079 \\
\hline
\end{tabular}

dissolution foaming of PMMA. ${ }^{[31]}$ It was suggested that the microcellular pores appear due to micro-sized sepiolite aggregates. The well-dispersed sepiolites account for the presence of nanocellular pores. The second and third rows show images of the same materials at increased magnification.

The main parameters characterizing the cellular structure of all the material systems produced in this study are summarized in Table 3. Due to the difference in size between the largest and the smallest cells in the materials with bimodal cell size distribution, we identify two sets of cells: the main (nanocellular, from 300 to $500 \mathrm{~nm}$ ) and the secondary (microcellular) structures. The microcellular pores were measured using SEM micrographs with the magnification of the images shown in the second row of Figure 1 (cell size around 1-10 $\mu \mathrm{m}$ ). The volumetric fraction of nano-sized cells $\left(V_{\text {nano }}\right.$ in Table 3 ) is greater than $50 \%$ for all the materials and, for this reason, the nanocellular population is considered to be the dominant one.

Bimodal micro- and nanocellular materials with average cell sizes ranging from 330 to $500 \mathrm{~nm}$ in the nano-sized cell population are obtained, whereas for the micro-sized cell population the cell size ranges from 3 to $7 \mu \mathrm{m}$. The nanocellular cell populations are more homogeneous, with $S D_{1} / \phi_{1}$ values around $0.5-0.7$, while the microcellular population is strongly heterogeneous with values for $S D_{2} / \phi_{2}$ higher than 1 . It is observed that, for the high-density materials (samples 1 to 5), an increased sepiolite content leads to a mild reduction of the average cell size. For the lower density materials, this effect is less obvious. For a given sepiolite concentration, the cell size tends to increase when density is reduced. Regarding the cell nucleation density, an increase of the nucleation in three orders of magnitude with respect to the pure PMMA is detected when sepiolites are added. The cellular materials were found to be closed-celled as the measured open cell contents were lower than $10 \%$ for all the material systems. In addition, the materials can be considered as isotropic because the anisotropy ratio is close to 1 for all the systems under study.

Regarding the homogeneity of the samples, it was found that all the samples showed a uniform cellular structure along the thickness, once the solid skin was removed (see Figure S3, Supporting Information).

\subsection{Uniaxial Compression Tests}

\subsubsection{Effect of Relative Density}

Figure 2 shows an example of the nominal stress versus nominal strain curves obtained for the uniaxial compression tests of the solid and cellular nanocomposites. The solid PMMA is compared with the nanocomposite $2 \%$-S, together with their corresponding cellular materials at high relative density (close to 0.5 ). The solid and cellular materials initially deform in a linear, elastic manner up until the yield point after which softening and subsequent hardening is observed. ${ }^{[46]}$ The elastic (secant) modulus $E$ is measured from the slope of the initial

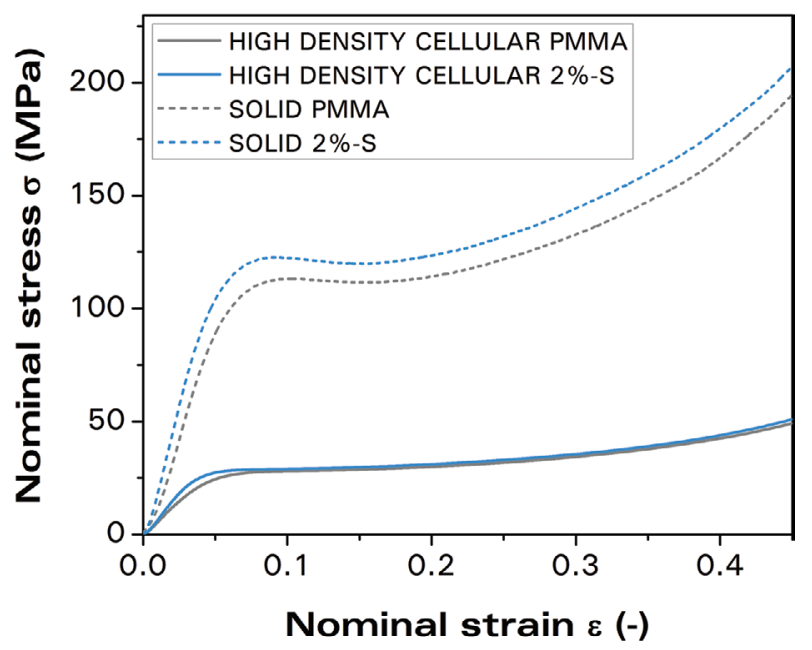

Figure 2. Example of stress-strain curves obtained during uniaxial compression of the solid materials and cellular samples with high relative density (around 0.5) based on the PMMA and 2\%-S material systems. 
a)

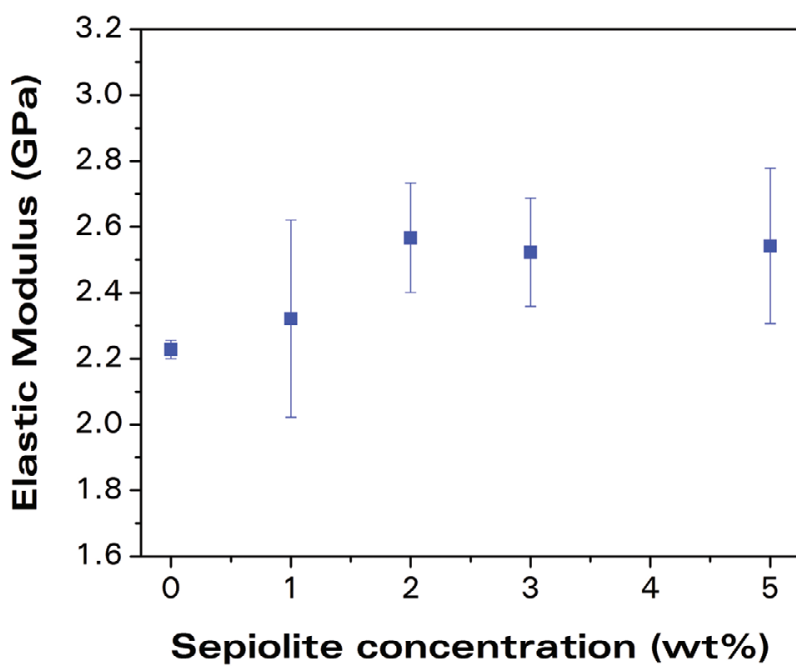

b)

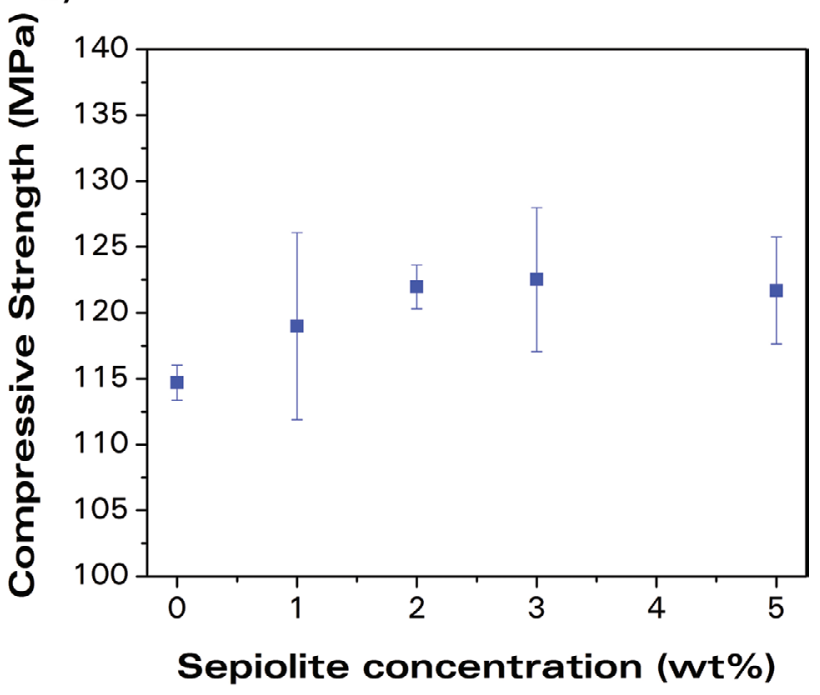

Figure 3. a) Elastic modulus and b) compressive yield strength of the solid nanocomposites as a function of sepiolite concentration.

linear region. The compressive yield strength $\sigma_{\gamma}$ corresponds to the peak load before softening.

Figure 3 shows the elastic modulus and the compressive yield strength of the solid nanocomposites as a function of sepiolite content. It is observed that both properties increase as the sepiolite content increases up to a content in the range of 2 to 3 wt\%. Increasing the sepiolite content to $5 \mathrm{wt} \%$ does not result in a further increase of the modulus and strength. These trends represent the typical behavior of polymer nanocomposites: the mechanical properties are enhanced when the filler concentration increases, but there is a critical filler concentration at which there is no further enhancement of the mechanical properties. ${ }^{[47]}$ We observe that the addition of sepiolites induces enhancement of the mechanical properties of the PMMA in uniaxial compression. In particular, for the composite $2 \%$-S an increase of $15 \%$ in the elastic modulus and a $5 \%$ in the compressive strength are observed compared to the PMMA without sepiolites. These observations are in agreement with previous reports of an increased strength and modulus when sepiolite particles are added to a polymer matrix. ${ }^{[48-50]}$ In the Supporting Information, several analytical models are used to capture the measured elastic modulus versus relative density trends.

To evaluate the mechanical properties of the cellular materials, the relative elastic modulus $\left(E_{r}\right)$ and compressive strength $\left(\sigma_{\gamma, r}\right)$ are calculated according to Equations (5) and (6), respectively, where $E$ and $\sigma_{\gamma}$ are the properties of the cellular materials and $E_{s}$ and $\sigma_{\gamma, s}$ are the properties of the solid material with the same sepiolite concentration.

$$
\begin{aligned}
& E_{r}=\frac{E}{E_{s}} \\
& \sigma_{\gamma, r}=\frac{\sigma_{\gamma}}{\sigma_{\gamma, s}}
\end{aligned}
$$

The measured trends for the relative modulus versus relative density and the compressive strength versus relative density for the cellular nanocomposites and the cellular PMMA are plotted in Figure $4 a, c$, respectively. Slightly higher values of the relative modulus for the $1 \%-\mathrm{S}, 2 \%-\mathrm{S}$, and $3 \%-\mathrm{S}$ composites at a relative density close to 0.5 are observed. In particular, the relative modulus for the composites $1 \%-\mathrm{S}, 2 \%-\mathrm{S}$, and $3 \%-\mathrm{S}$ are $11 \%, 23 \%$, and $20 \%$ higher than that of the pure PMMA at the same density, respectively. However, the relative modulus at lower densities is observed to be independent of sepiolite concentration. It was found that the relative yield strength mildly decreases as a function of sepiolite concentration for all investigated relative densities.

It has been reported by several authors ${ }^{[51-54]}$ that a given material property of a cellular polymer $\left(P_{c}\right)$ is related to the material property of the solid polymer $\left(P_{s}\right)$ by

$\frac{P_{c}}{P_{s}}=K \rho_{r}^{n}$

where $K$ and $n$ are constants to be experimentally determined. For most cellular polymers $K$ is close to 1 , while $n$ is related to the cellular morphology of the cellular material, being close to 1 for closed cell structures and in the range of 1.5 to 2 for open cell and high density materials. ${ }^{[11]}$ The trends predicted by Equation (7) for $K=1$ are shown in Figure 4a (relative modulus) and in Figure 4c (relative strength) for different values of $n$. One can observe that the relative modulus versus relative density trend of the cellular materials with a high density is captured by Equation (7) for $n$ close to 2. In contrast, for the cellular materials with lower relative densities, a $n$ value of 1.5 gives a more accurate fit. The relative compressive strength versus relative density trends (see Figure 4c) are captured by $n$ between 1.5 and 2 for all material systems.

The effect of the relative density is evaluated by fitting Equation (7) to the measured relative modulus and relative strength data, giving a fitted $n$ value for each material system with a given sepiolite content (see Figure 4b,d). Note that, for this analysis, the system 5\%-S was excluded as there were no data points at low densities. 
a)

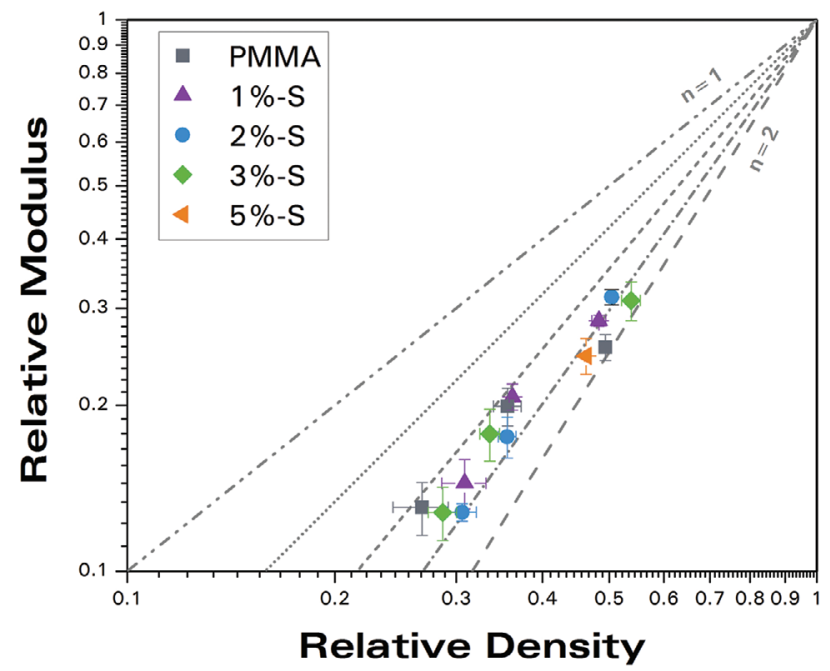

c)

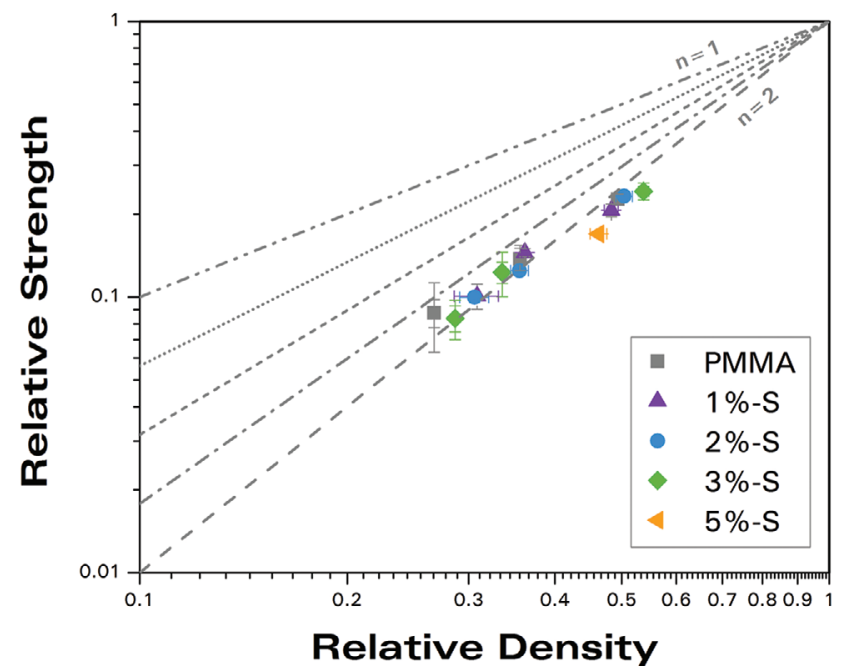

b)

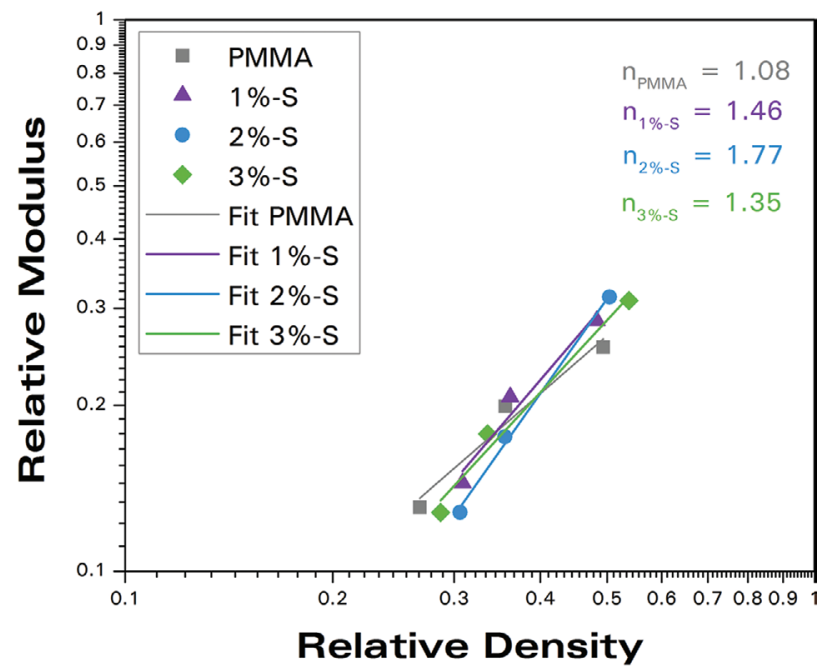

d)

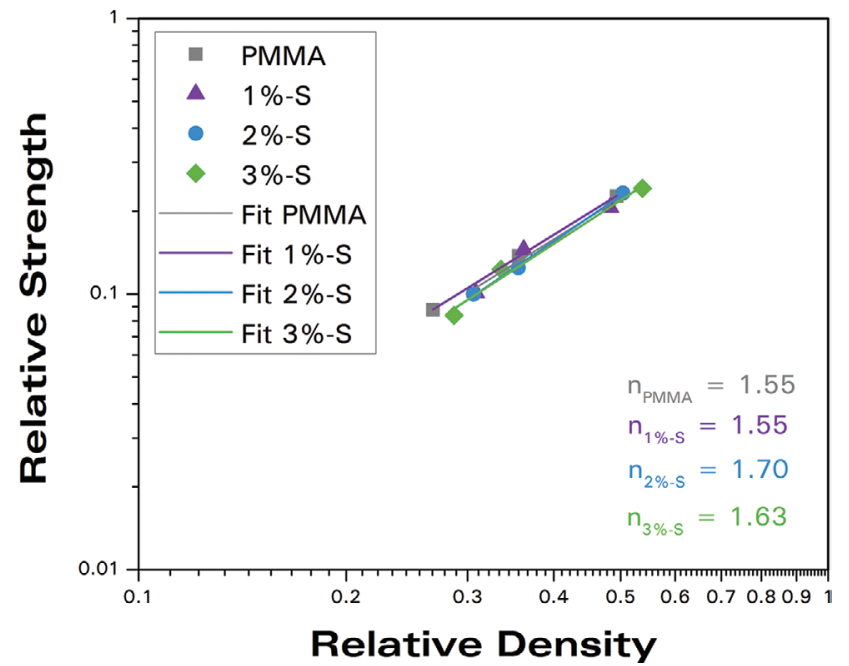

Figure 4. a) Relative modulus of the cellular PMMA and the nanocomposites as a function of the relative density with contours predicted by Equation (7) for $K=1$ and $n$ values ranging from 1 to 2; b) Predicted trends by fitting Equation (7) to the relative modulus data with corresponding $n$ values; c) Relative compressive strength of the cellular PMMA and the nanocomposites as a function of the relative density with contours predicted by Equation (7) for $K=1$ and $n$ values ranging from 1 to 2; b) Predicted trends by fitting Equation (7) to the relative strength data with resulting fitted $n$ values.

An average $n$ value is calculated from the fitted $n$ values for each material system: $n=1.42$ for the modulus and $n=1.61$ for the strength. Equation (7) is then fitted to the measured relative modulus of each material system and the measured relative strength of each material system with the average $n$ by varying $K$. We will use $A$ to denote the $K$ constant for the modulus and $B$ for the $K$ constant for the compressive strength. The obtained values for $A$ and $B$ for each sepiolite concentration are divided by $A_{0}$ and $B_{0}$, the value of $A$ and $B$ for the cellular PMMA without sepiolite particles, respectively, as shown in Figure 5a (modulus) and Figure 5b (strength). The measured modulus of the solid nanocomposite divided by the modulus of the solid PMMA is plotted as a function of the sepiolite concentration in Figure 5a. The strength of the solid nanocomposite divided by the strength of the solid PMMA is plotted as a function of the sepiolite concentration in Figure 5b. From Figure 5a,b we conclude that, although there is an enhancement of the relative modulus and the relative strength for the solids due to the addition of the sepiolite particles, there is no reinforcement found for the cellular nanocomposites. The trends shown in Figure $5 \mathrm{a}, \mathrm{b}$ are replotted with error bars in the Supporting Information.

\subsubsection{Reinforcement at High Relative Density}

In Figure 4a one can observe that, at high relative densities, the modulus values of the nanocomposites are higher than those of the cellular PMMA. We now perform the same analysis as in Section 3.2.1, but assume $n=2$. The $n=2$ assumption 
a)

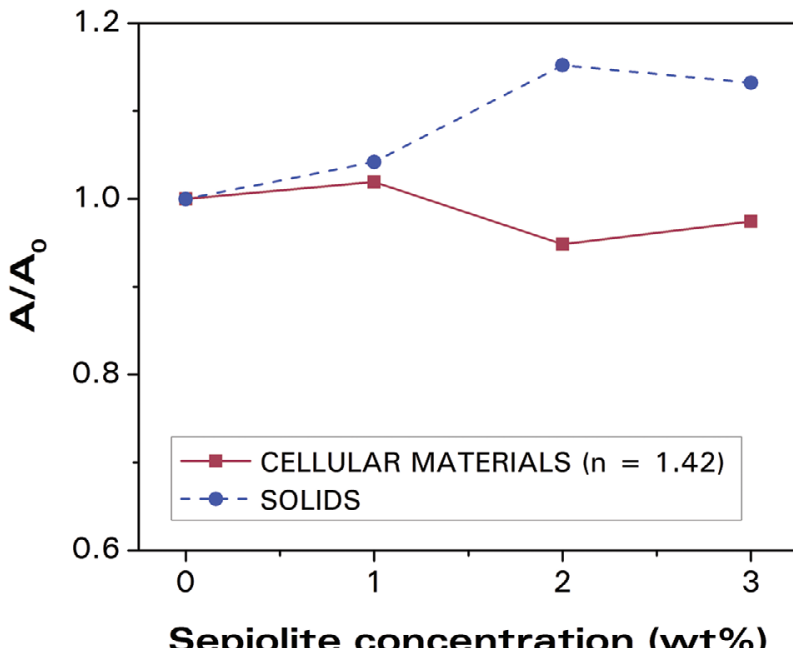

b)

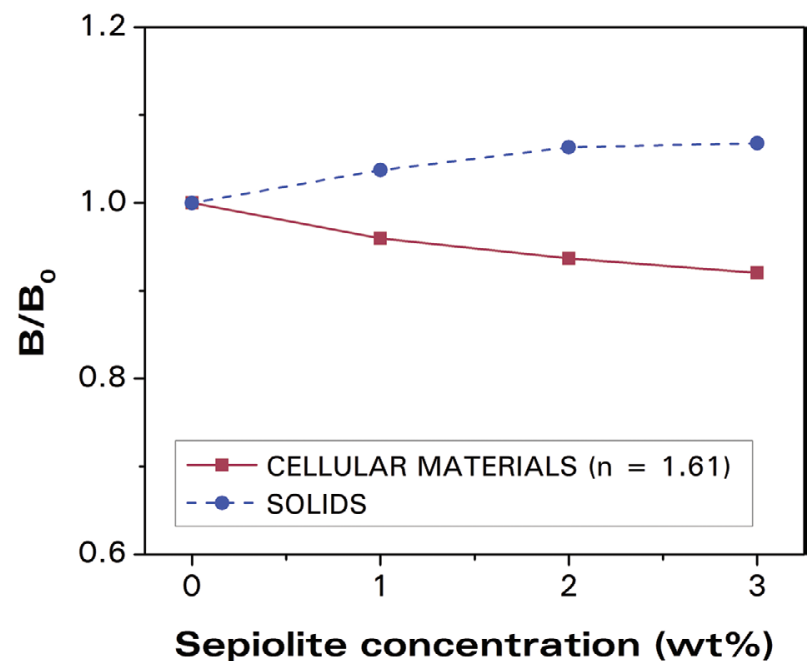

Figure 5. a) $A / A_{0}$ (elastic modulus) and b) $B / B_{0}$ (compressive strength) as a function of the sepiolite concentration for the cellular materials and the solids.

for high relative densities $(>0.5)$ is in agreement with several previous works. ${ }^{[3,55-57]}$ For this analysis, as only the high density materials are considered, the samples with $5 \%-\mathrm{S}$ are also included. Figure 6 shows the results of this analysis for the high density materials. One can observe that $A / A_{0}$ for the cellular nanocomposites with a high density is above unity for all sepiolite concentrations. A clear reinforcement effect is observed for the elastic modulus for the nanocomposites $1 \%-\mathrm{S}$ and $2 \%-\mathrm{S}$, for which the parameter $A / A_{0}$ takes values as high as 1.18 , that is, an $18 \%$ enhancement of the modulus by the addition of $2 \mathrm{wt} \%$ sepiolites. No reinforcement is detected for the compressive strength by assuming $n=2$ for the high-density materials.

The observed enhancement of the elastic modulus values of the high density materials can be attributed to the presence

a)

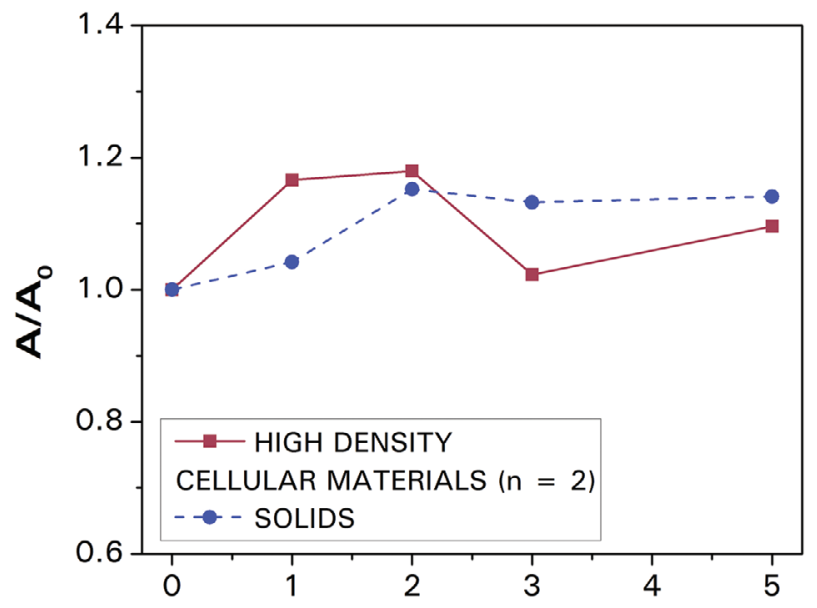

Sepiolite concentration (wt\%) of the sepiolite particles. Yet, the bimodal cell size distribution and the nano-sized cells could also lead to a potential enhancement of the mechanical properties, see for instance, Notario and colleagues ${ }^{[9]}$ and Miller and coworkers. ${ }^{[11]}$ To verify whether cell size and cell size distribution play a role, additional microcellular materials with $3 \mathrm{wt} \%$ of sepiolites were produced and tested in uniaxial compression (see the Supporting Information). It was observed that the measured values for the elastic modulus of the bimodal and the microcellular samples were close to each other. These outcomes suggest that the observed enhancement is not caused by the nano-sized cell size and/or the bimodal cell size distribution. Instead, we concluded that the observed reinforcement is due to the addition of sepiolite particles in presence of a cellular structure. This effect was also observed by Laguna-Gutierrez and co-workers who measured

b)

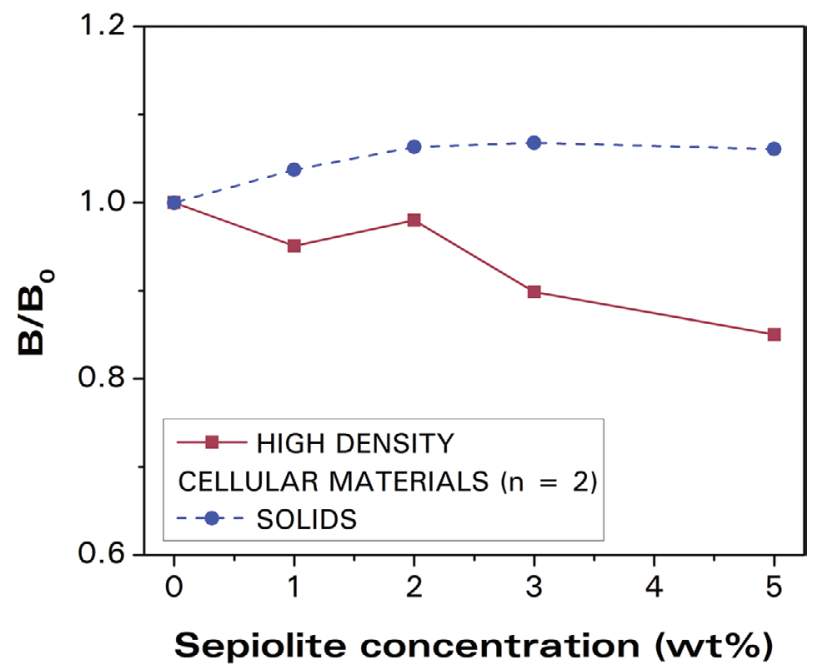

Figure 6. a) $A / A_{0}$ (elastic modulus) and b) $B / B_{0}$ (compressive strength) as a function of the sepiolite concentration for the cellular materials with high relative density and the solids. 

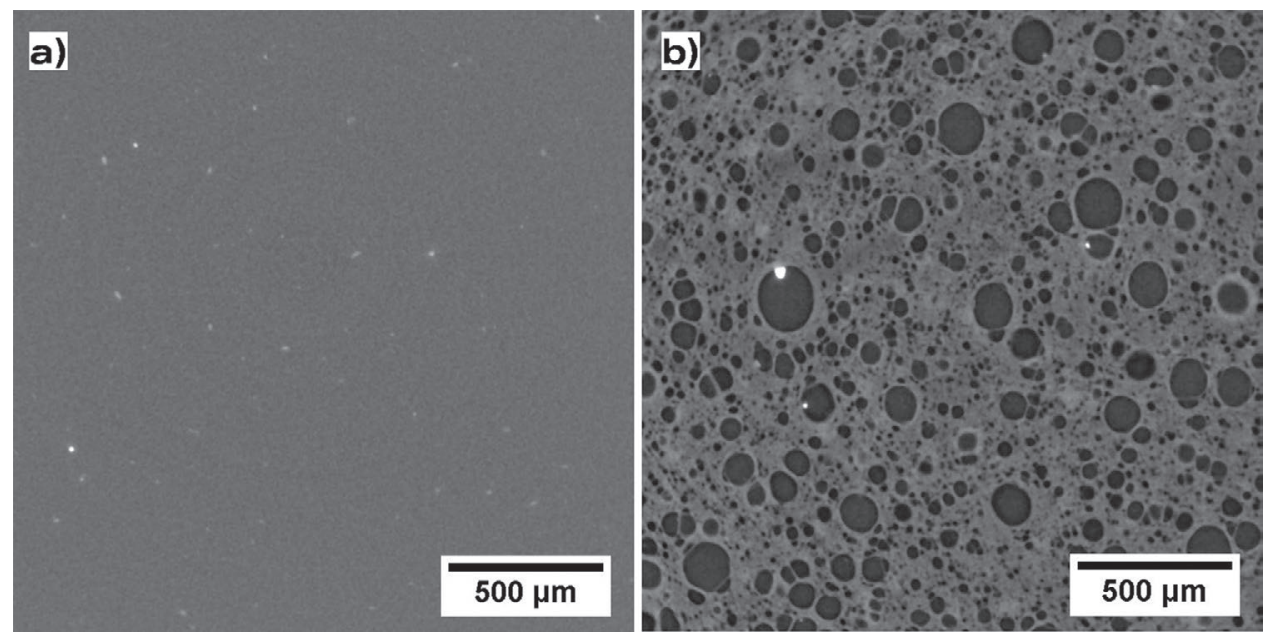

Figure 7. Reconstructed tomography images of $2 \%-\mathrm{S}$ : a) solid nanocomposite and b) cellular nanocomposite with a relative density close to 0.5 .

the elastic modulus of low density foamed polyethylene reinforced with silica nanoparticles. ${ }^{[58]}$

Another possible rationale behind the reinforcement detected in the cellular nanocomposites compared to the solid nanocomposites with the same sepiolite content is the improved dispersion of the particles in the cellular materials due to the foaming process. Multiple studies have demonstrated that foaming can lead to better dispersion of particles. ${ }^{[59-62]}$ To validate this hypothesis, the number of particle aggregates was determined before and after the foaming process for the material with $2 \mathrm{wt} \%$ of sepiolites (for which the highest enhancement of the modulus was observed at a relative density close to 0.5 ) using tomography and image analysis. Figure 7 shows an example of the reconstructed images for the solid and a cellular material with a relative density close to 0.5 . The bright dots represent areas of higher density (note that the pores, filled with air, are black). So the bright dots are the sepiolites aggregates, with dimensions larger than $2.5 \mu \mathrm{m}$ (corresponding to the spatial resolution of the computed tomography instrument). These aggregates represent $0.57 \mathrm{wt} \%$ in the solid material, whereas they only account for $0.15 \mathrm{wt} \%$ in the cellular material. Moreover, the number of large aggregates decreases by foaming. These outcomes indicate that the particles are less aggregated in the cellular samples than in the solids. This effect is related to the stretching suffered by the polymer chains during the cell growth. ${ }^{[61-64]}$ The enhanced dispersion is expected to enhance the mechanical properties of the solid phase. As a result, the reinforcement found for the modulus of the cellular nanocomposites is stronger than in the solid nanocomposites, especially for the systems with 1 and $2 \mathrm{wt} \%$ of sepiolites.

Another potential rationale behind the observed enhancement of the elastic modulus values of the high density materials is related to the position of the aggregates in the cellular materials. Based on SEM micrographs and tomography images, we observe that most of the micro-sized aggregates are isolated from the solid phase and located within the microcellular pores as a result of the foaming process (see Figure 8). The solid phase in the cellular material is therefore reinforced by the small well-dispersed sepiolites, whereas the big aggregates (potentially reducing the mechanical properties of the solid) are not affecting the mechanical performance, as they are located in the microcellular pores. This observation suggests that the presence of a cellular structure in a nanocomposite can balance out, up to some extent, the negative influence of the particle aggregates on the mechanical properties.
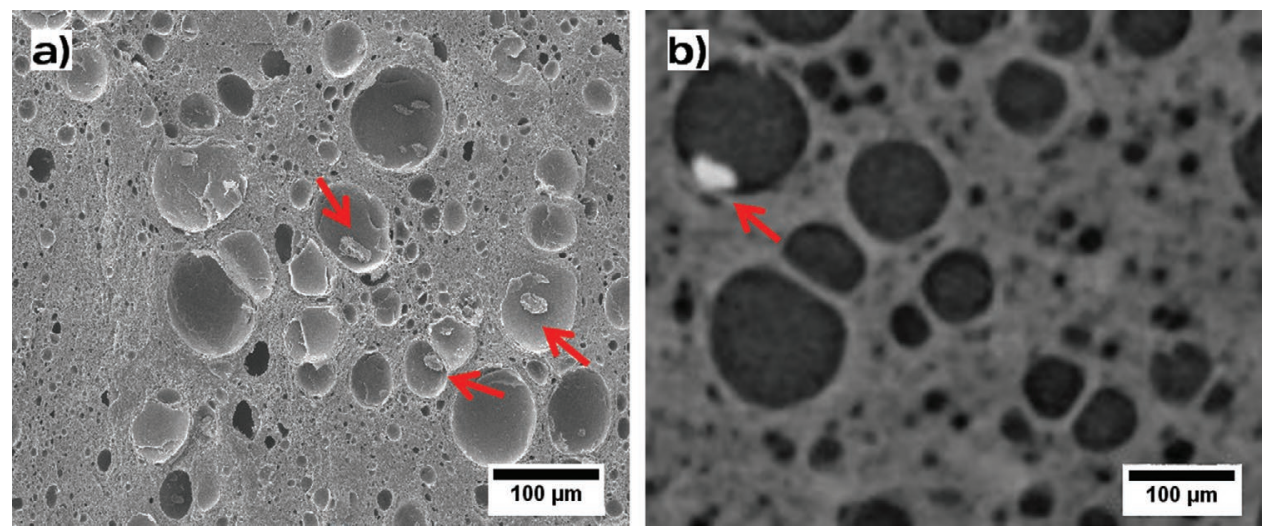

Figure 8. Example of aggregates inside the microcellular pores (red arrows): a) SEM micrograph of the cellular material 5\%-S with relative density close to 0.5 and b) reconstructed tomography of the cellular material $2 \%-S$ with relative density around 0.5 . 


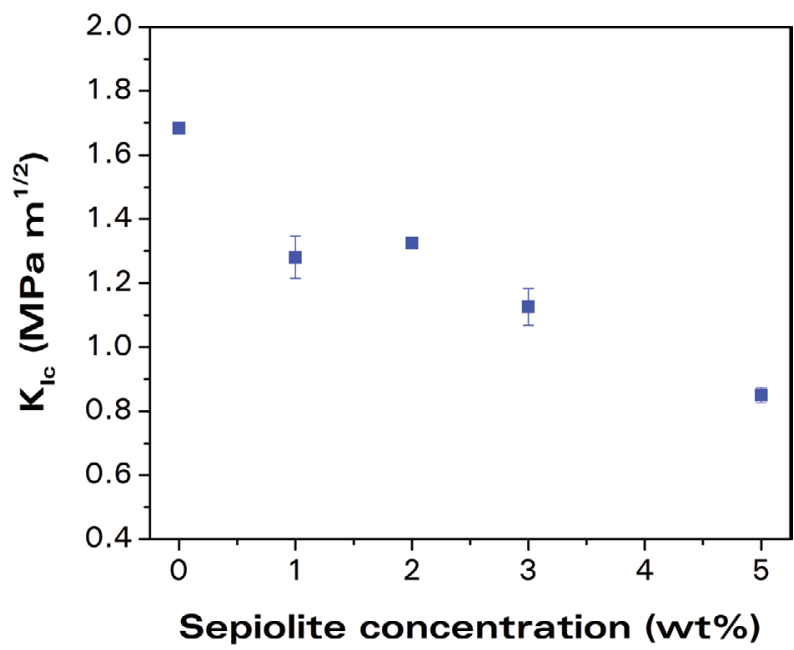

Figure 9. Fracture toughness $\left(K_{I C}\right)$ of the unfilled PMMA and of the solid nanocomposites as a function of sepiolite content.

\subsection{Fracture Toughness}

\subsubsection{Effect of Relative Density}

Figure 9 shows the measured ${ }^{[65]} K_{I C}$ of the solid nanocomposites and the pure PMMA as a function of sepiolite concentration. The measured fracture toughness of the unfilled PMMA is close to $1.7 \mathrm{MPa} \mathrm{m}^{1 / 2}$, in agreement with reported values for $K_{I C}$ of PMMA in the literature. ${ }^{[66]}$ It is observed that the fracture toughness decreases as the sepiolite content increases. This result is in agreement with earlier works reporting that high aspect ratio fillers such as sepiolites cause embrittlement of the nanocomposite. ${ }^{[66,67]}$

The fracture toughness of the cellular materials is evaluated by calculating the relative fracture toughness $\left(K_{I C, r}\right)$ according

a)

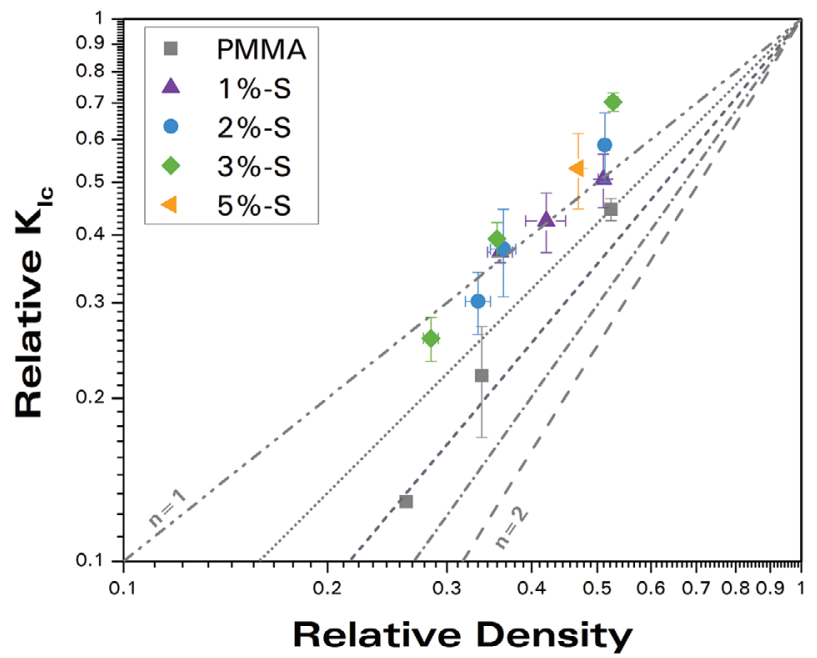

to Equation (8), where $K_{I C}$ is the toughness of the cellular materials and $K_{I C, s}$ is the property of the solid material with the same sepiolite concentration.

$K_{I C, r}=\frac{K_{I C}}{K_{I C, s}}$

The trends for the relative fracture toughness versus relative density of the cellular nanocomposites and the cellular PMMA are plotted in Figure 10a. All the samples present a brittle fracture behavior (see the Supporting Information for SEM images of the fracture surface). Over the complete density range, the measured relative toughness of the cellular materials with sepiolite particles is higher than the measured relative fracture toughness of the cellular materials without sepiolites. At high relative density, the relative fracture toughness of the composites $1 \%-\mathrm{S}, 2 \%-\mathrm{S}, 3 \%-\mathrm{S}$, and $5 \%-\mathrm{S}$ are higher than that of the PMMA in 14\%, 31\%, 58\%, and 19\%, respectively. At lower density $(0.34)$, the differences can be as high as $79 \%$ for the sample $3 \%-\mathrm{S}$. The trends predicted by Equation (7) for $K=1$ are also shown in Figure 10a for different $n$ values.

Equation (7) is fitted to every material system, see Figure 10b. An average $n$ value is calculated from the fitted $n$ values: $n=1.43$. Equation ( 8 ) is subsequently fitted to the measured fracture toughness values for each material system for $n=1.43$ by varying $K$. We will use $C$ to denote the $K$ constant for the fracture toughness. The obtained $C$ values for each sepiolite concentration are divided by $C_{0}$, the value for $C$ for the cellular PMMA without sepiolite particles, as shown in Figure 11. The fracture toughness of the solid nanocomposites divided by the fracture toughness of the solid PMMA as a function of the sepiolite content is shown in Figure 11 too. From Figure 11 we conclude that, although there is a significant decrease of the fracture toughness of the solids as the sepiolite concentration increases, addition of sepiolite particles to the cellular materials leads to an enhanced fracture toughness. This enhancement

b)

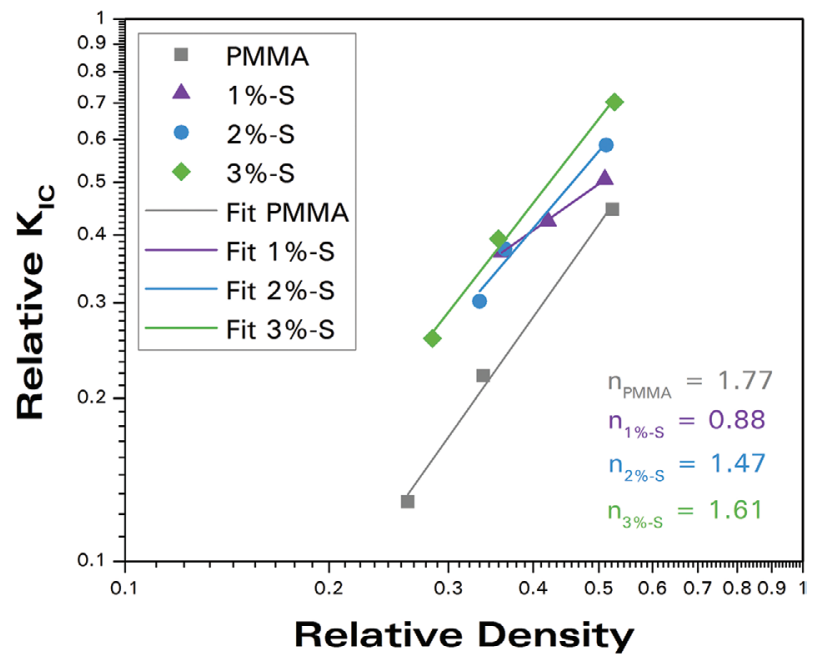

Figure 10. a) Relative fracture toughness $\left(K_{I C}\right)$ of the cellular PMMA and the nanocomposites as a function of the relative density with contours predicted by Equation (7) for $K=1$ and varying $n$ values ranging from 1 to 2; b) Fits of the relative modulus according to Equation (7) and resulting fitted $n$ values. 


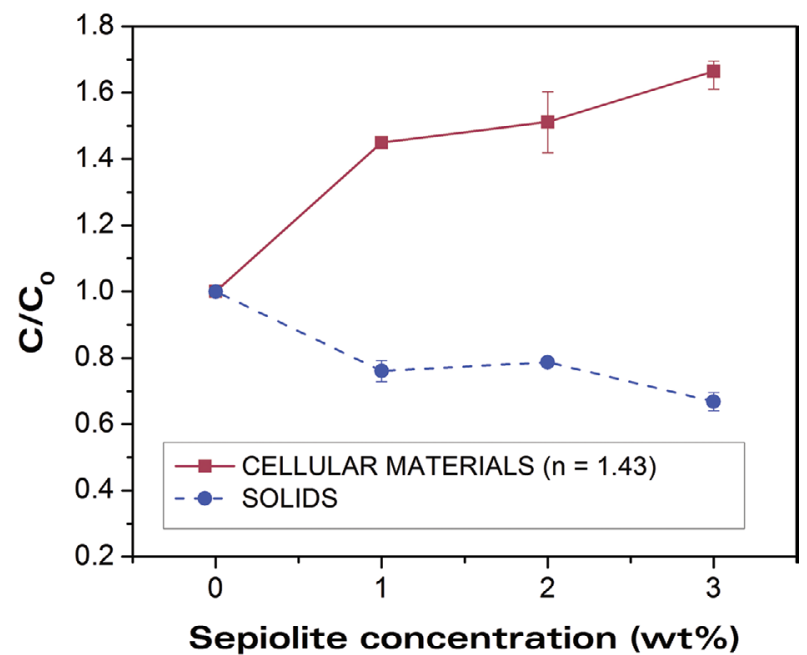

Figure 11. $C / C_{0}$ (fracture toughness constants) as a function of the sepiolite concentration for the cellular materials and the solids.

found in the cellular materials could be a consequence of the presence of a bimodal cell size distribution in combination with nano-sized cell sizes. To evaluate this effect, the fracture toughness of an additional set of microcellular materials with a $3 \mathrm{wt} \%$ sepiolite concentration was measured (Supporting Information). It was found that the cell size distribution had no effect on the toughness of the samples. These outcomes therefore suggest that a better dispersion of the sepiolites in the cellular nanocomposites and the presence of the aggregates inside the microcellular pores lead to an improved relative fracture toughness, or in other words, the negative effects of the particle aggregates in the fracture toughness of the solids are hidden in the cellular materials.

\section{Conclusions}

The present study reveals that the addition of up to $3 \mathrm{wt} \%$ of nanoparticles made from hydrated magnesium silicates (so-called sepiolites) to solid PMMA leads to a mild increase in modulus (by 15\%) and in yield strength (by 5\%) but to a decrease in bulk fracture toughness (by 40\%). The effect of sepiolite content upon the mechanical properties of PMMA cellular materials with a bimodal cellular structure with nanometric cells $(300$ to $500 \mathrm{~nm}$ ) is more complex. First, the porosity of $50 \%$ to $75 \%$ exists in a bimodal cell size distribution with one population of cells on the nanoscale (cell sizes below $500 \mathrm{~nm}$ ) and the other on the microscale. The presence of porosity degrades the modulus, strength and toughness for both pure PMMA and for the PMMA-sepiolite composites. In order to isolate the effect of sepiolite content on the relative properties of the foamed PMMA, it is necessary to factor-out the effect of porosity. When this is done, it was found that the relative modulus is independent of sepiolite concentration, whereas the addition of sepiolites results in a mild decrease in relative strength. The relative fracture toughness strongly increases as a function of sepiolite content. Moreover, for the cellular nanocomposites with a relatively low porosity (close to 50\%), the addition of sepiolite particles leads to an increase in the relative modulus. Our observations suggest that the enhancement of the relative fracture toughness and the relative modulus (for the porosity of 50\%) of the nanocellular PMMA by the addition of sepiolites is caused by the improved dispersion of the sepiolites due to the foaming process and by the migration of the micro-sized sepiolite aggregates to the micro-sized pores during foaming.

\section{Supporting Information}

Supporting Information is available from the Wiley Online Library or from the author.

\section{Acknowledgements}

Financial support from the FPU grant FPU14/02050 (V.B.) from the Spanish Ministry of Education, the Junta of Castile and Leon grant (J.M.-d.L.) and the Engineering and Physical Sciences Research Council (UK) award 1611305 (F.V.L.) is gratefully acknowledged. Financial assistance from MINECO, FEDER, UE (MAT2015-69234-R), the Junta de Castile and Leon (VA275P18), the ERC MULTILAT grant 669764, and SABIC are gratefully acknowledged too. The authors would also like to thank Dr. Martin van Es from SABIC for the technical assistance and fruitful discussions and Tolsa (Madrid, Spain) for supplying the sepiolites for this study.

\section{Conflict of Interest}

The authors declare no conflict of interest.

\section{Keywords}

mechanical properties, nanocellular foams, nanocellular polymers, nanocomposites, poly (methyl methacrylate)

Received: January 17, 2019

Revised: March 18, 2019

Published online: April 25, 2019

[1] B. Notario, J. Pinto, M. A. Rodriguez-Perez, Prog. Polym. Sci. 2016, 78-79, 93.

[2] B. Notario, J. Pinto, E. Solorzano, J. A. de Saja, M. Dumon, M. A. Rodriguez-Perez, Polymer (Guildf) 2015, 56, 57.

[3] G. Wang, C. Wang, J. Zhao, G. Wang, C. B. Park, G. Zhao, Nanoscale 2017, 9, 5996.

[4] J. Martin de-Leon, V. Bernardo, M. A. Rodriguez-Perez, Polymers (Basel) 2016, 8, 1.

[5] S. Perez-Tamarit, B. Notario, E. Solorzano, M. A. Rodriguez-Perez, Mater. Lett. 2017, 210, 39.

[6] L. Li, L. Schulte, L. D. Clausen, K. M. Hansen, G. E. Jonsson, S. Ndoni, ACS Nano 2011, 5, 7754.

[7] J. Pinto, M. Dumon, M. A. Rodriguez-Perez, R. Garcia, C. Dietz, J. Phys. Chem. C 2014, 118, 4656.

[8] G. Q. Lu, X. S. Zhao, in Nanoporous Mater. Sci. Eng., Imperial Collegue Press, London 2004.

[9] B. Notario, J. Pinto, M. A. Rodríguez-Perez, Polymer (Guildf) 2015, 63, 116. 
[10] M. F. Ashby, Materials Selection in Mechanical Design, 3rd ed., Butterworht-Heinemann, Oxford 2005.

[11] D. Miller, V. Kumar, Polymer (Guildf) 2011, 52, 2910.

[12] H. Guo, Solid-State Polymer Nanofoams, University of Washington, Washington 2015.

[13] G. Wang, J. Zhao, L. H. Mark, G. Wang, K. Yu, C. Wang, C. B. Park, G. Zhao, Chem. Eng. J. 2017, 325, 632.

[14] G. Wang, G. Zhao, L. Zhang, Y. Mu, C. B. Park, Chem. Eng. J. 2018, $350,1$.

[15] J. A. Reglero Ruiz, M. Dumon, J. Pinto, M. A. Rodriguez-Perez, Macromol. Mater. Eng. 2011, 296, 752.

[16] H. Fischer, Mater. Sci. Eng. 2003, 23, 763.

[17] F. Yang, G. L. Nelson, J. Appl. Polym. Sci. 2004, 91, 3844

[18] A. S. Blivi, F. Benhui, J. Bai, D. Kondo, Polym. Test. 2016, 56, 337.

[19] S. Pavlidou, C. D. Papaspyrides, Prog. Polym. Sci. 2008, 33, 1119.

[20] M. Vahidi, H. Azizi, Cell. Polym. 2017, 36, 251.

[21] V. Mittal, Polymer Nanocomposite Foams, CRC Press, Boca Raton 2014.

[22] C. C. Ibeh, M. Bubacz, J. Cell. Plast. 2008, 44, 493.

[23] H. Janani, M. H. N. Famili, Polym. Eng. Sci. 2010, 50, 1558.

[24] W. Zhai, J. Yu, L. Wu, W. Ma, J. He, Polymer (Guildf) 2006, 47, 7580.

[25] J. Yang, L. Huang, Y. Zhang, F. Chen, P. Fan, M. Zhong, S. Yeh, Ind. Eng. Chem. Res. 2013, 52, 14169.

[26] S. Siripurapu, J. M. Desimone, S. A. Khan, R. J. Spontak, N. Carolina, N. Carolina, Macromolecules 2005, 38, 2271.

[27] Y. Fujimoto, S. S. Ray, M. Okamoto, A. Ogami, K. Yamada, K. Ueda, Macromol. Rapid Commun. 2003, 24, 457.

[28] Y. H. Lee, C. B. Park, K. H. Wang, J. Cell. Plast. 2005, 41, 487.

[29] L. Urbanczyk, C. Calberg, C. Detrembleur, C. Jérôme, M. Alexandre, Polymer (Guildf) 2010, 51, 3520.

[30] S. Costeux, L. Zhu, Polymer (Guildf) 2013, 54, 2785.

[31] V. Bernardo, J. Martin-de León, E. Laguna-Gutiérrez, M. Á. Rodríguez-Pérez, Eur. Polym. J. 2017, 96, 10.

[32] S. K. Yeh, Y. C. Liu, C. C. Chu, K. C. Chang, S. F. Wang, Ind. Eng. Chem. Res. 2017, 56, 8499.

[33] A. Alvarez, J. Santaren, A. Esteban-Cubillo, P. Aparicio in Development in Palygorskite-Sepiolite Research (Eds: E. Galan, A. Singer), Elsevier B.V., Oxford 2011.

[34] E. Ruiz-Hitzky, J. Mater. Chem. 2001, 11, 86.

[35] J. Santaren, A. Alvarez, A. Esteban-Cubillo, B. Notario, D. Velasco, M. A. Rodriguez-Perez, in FOAMS 2012, 2012, 1.

[36] N. García, J. Guzman, E. Benito, A. Esteban-Cubillo, E. Aguilar, J. Santaren, P. Tiemblo, Langmuir 2011, 27, 3952.

[37] V. Kumar, N. P. Suh, Polym. Eng. Sci. 1990, 30, 1323.

[38] K. Nadella, V. Kumar, W. Li, Cell. Polym. 2005, 24, 71.

[39] J. Pinto, E. Solorzano, M. A. Rodriguez-perez, J. A. De Saja, J. Cell. Plast. 2013, 49, 555.

[40] V. Kumar, Process Synthesis for Manufacturing Microcellular Thermoplastic Parts, Massachusetts Institute of Technology, Cambridge 1988.

[41] C. A. Mandarim-de-Lacerda, Ann. Brazilian Acad. Sci. 2003, 75, 469.
[42] N. C. Hilyard, A. Cunningham, Low Density Cellular Plastics-Physical Basis of Behaviour, Chapman And Hall, London 1994.

[43] E. Solórzano, J. Pinto, S. Pardo, F. Garcia-Moreno, M. A. RodriguezPerez, Polym. Test. 2013, 32, 321.

[44] J. Escudero, E. Solorzano, M. A. Rodriguez-Perez, F. GarciaMoreno, J. A. de Saja, Cell. Polym. 2009, 28, 289.

[45] ASTM International Standard D5045-14. Standard Test Methods for Plane-Strain Fracture Toughness and Strain Energy Release Rate of Plastic Materials.

[46] F. Van Loock, N. A. Fleck, Polym. (United Kingdom) 2018, 148, 259.

[47] L. Chen, D. Rende, L. S. Schadler, R. Ozisik, J. Mater. Chem. A 2013, 1, 3837.

[48] X. Li, Q. Wang, H. Li, H. Ji, X. Sun, J. He, J. Sol-Gel Sci. Technol. 2013, 67, 646 .

[49] D. Garcia-Lopez, J. F. Fernandez, J. C. Merino, J. Santaren, J. M. Pastor, Compos. Sci. Technol. 2010, 70, 1429.

[50] J. Ma, J. A. Darr, Eur. Polym. J. 2007, 43, 4931.

[51] L. J. Gibson, M. Ashby, Cellular Solids: Structure and Properties, Cambridge University Press, Cambridge 1997.

[52] N. J. Mills, H. X. Zhu, J. Mech. Phys. Solids 1999, 47, 669.

[53] A. Lopez-Gil, C. Saiz-Arroyo, J. Tirado, M. A. Rodriguez-Perez, J. Appl. Polym. Sci. 2015, 132, 1.

[54] M. Frydrych, C. Wan, R. Stengler, U. O. Kelly, B. Chen, J. Mater. Chem. 2011, 30, 9103.

[55] V. Kumar, M. Vanderwel, J. Weller, K. A. Seeler, J. Eng. Mater. Technol. 1994, 116, 439.

[56] J. Fu, C. Jo, H. E. Naguib, Cell. Polym. 2005, 24, 177.

[57] C. Saiz-Arroyo, M. A. Rodriguez-Perez, J. Tirado, A. López-Gil, J. A. de Saja, Polym. Int. 2013, 62, 1324.

[58] E. Laguna-Gutierrez, C. Saiz-Arroyo, J. I. Velasco, M. A. RodriguezPerez, Eur. Polym. J. 2016, 81, 173.

[59] J. I. Velasco, M. Antunes, O. Ayyad, C. Saiz-Arroyo, M. A. RodriguezPerez, F. Hidalgo, J. A. de Saja, J. Appl. Polym. Sci. 2007, 105, 1658.

[60] J. I. Velasco, M. Antunes, O. Ayyad, J. M. Lopez-Cuesta, P. Gaudon, C. Saiz-Arroyo, M. A. Rodriguez-Perez, J. A. de Saja, Polymer (Guildf) 2007, 48, 2098.

[61] E. Laguna-Gutierrez, R. Van Hooghten, P. Moldenaers, M. A. Rodriguez-Perez, J. Appl. Polym. Sci. 2015, 132, 42430.

[62] J. Escudero, B. Notario, C. Jimenez, M. A. Rodriguez-Perez, J. Appl. Polym. Sci. 2016, 133, 43432.

[63] W. Zhai, C. B. Park, M. Kontopoulou, Ind. Eng. Chem. Res. 2011, 50, 7282.

[64] A. Ameli, M. Nofar, C. B. Park, Carbon N. Y. 2014, 71, 206.

[65] The load versus indenter displacement trend for all $K_{I C}$ measurements of the solid and cellular material systems was linear up until fracture of the SENB specimens.

[66] H. Varela-Rizo, M. Weisenberger, D. R. Bortz, I. Martin-Gullon, Compos. Sci. Technol. 2010, 70, 1189.

[67] B. Cotterell, J. Y. H. Chia, K. Hbaieb, Eng. Fract. Mech. 2007, 74, 1054 